\title{
The Chinese Loess Plateau - Far and Wide
}

The Chinese Loess Plateau (CLP), the world's largest accumulation of loess, is a major geological feature of China $\left(4.4 \times 10^{5}\right.$ $\mathrm{km}^{2}$ ), and therefore a significant feature of Asia. It is generally considered to have been formed beginning around 2.5 my ago by eolian deposition of sediment from desert areas such as the Gobi and the Takla Makan which are located to the north and northwest - the direction of generally increasing bed thickness and grain size (Liu, 1985). Certainly the initial formation of this eolian feature represents a major shift in the climate of the area, as well as of the globe, in that the initial formation of the CLP is generally connected to the onset of the major continental glaciations that characterized the Pleistocene epoch. The displacement of such a huge amount of sediment over distances of hundreds of kilometers to the CLP from remote source areas implies that the atmosphere was extraordinarily dusty during periods of high transport. Even present-day, less intense dust storms originating out of the arid areas of China are sufficiently intense to have a specific name in downwind Japan "kosha events".

That the record of modern eolian dust transport extends beyond the borders of continental deserts has been known for decades, at least since Radczewski reported eolian quartz ("Wüstenquarz") in Atlantic sediments offshore of the Sahara (1939). Similarly, the band of quartz-rich sediment across the North Pacific at about the latitude of the westerlies was attributed to desert sources by Rex and Goldberg (1958), although the latter authors did not specifically mention the deserts of eastern Asia. Subsequent research on North Pacific sediments has specifically tied the marine record of dust to eastern Asia, and has shown that the flux of desert dust to the ocean has varied significantly with time, presumably reflecting changes in the East Asian climate and in the atmospheric conditions responsible for dust deflation and transport (Nakai et al., 1993; Leinen et al., 1994; Rea, 1994; Asahara et al., 1995).

We have more recently discovered in Greenland an even more distal record of the climate conditions associated with the CLP and its source deserts. It has been known for some time that the concentration of dust falling on high-latitude ice caps has varied greatly over time with high concentrations generally reflecting glacial periods, while lower concentrations characterize interglacial periods such as the present Holocene (Thompson and Mosley-Thompson, 1980). It was not, however, until the recent drilling of the long ice cores at Summit, Greenland, that this purely atmospheric record was discovered to contain variations in dust content of $10^{3}-10^{2}$ years du- ration within glacial periods (and perhaps within interglacials) that are almost as great as those variations associated with glacial-interglacials and occurring on $10^{5}-10^{4}$ year timescales. Furthermore, the transitions between different dust concentration levels, and the variations in climate that they represent, took place with extreme abruptness, on the order of 10 years. The causes of these extreme variations in the dust record, ranging over periods from $10^{1}$ to $10^{5}$ years, have been the subject of more speculation than analysis.

The approach that we and our colleagues have taken to the solution of this problem is to first determine from what continental location(s) the dust originates. In previous studies we used the Sr and Nd isotopic compositions of East Antarctic dust from three glacial periods to determine that it was derived from Patagonia (Grousset et al., 1992; Basile et al., 1997). This connection was established by comparing the isotopic characteristics of the ice-core dusts to those of eolian samples (loesses, desert sands and dusts) from all potential source areas. For our initial work on the Greenland ice-core dusts from the GISP2 core, we added clay mineralogy, which reflects the weathering regime and hence the climate in the source area, as well as the isotopic composition of $\mathrm{Pb}$, which, like $\mathrm{Sr}$ and $\mathrm{Nd}$, reflects the lithology and geologic age of the source area, as additional tracers. We analyzed these four, largely independent tracer characteristics of the 23-26 thousand-year old dust across a range of dust concentrations that varied by about one order of magnitude. We then compared these values to the fine fraction of about one hundred loess and desertic PSA samples from more than two dozen locations around the northern hemisphere, including samples from the CLP and one of its source areas, the Gobi Desert of Mongolia.

Assuming that our PSA samples adequately represent the northern hemisphere dust source areas, the results of these comparisons shows, rather unequivocally, that the dust that fell on Summit, Greenland from 23 to 26 thousand years ago, just prior to the Last Glacial Maximum, was derived from the CLP and its source area the Gobi, and probably other east Asian desert areas to the northwest (Biscaye et al., 1997). Furthermore, based on the fact that the apparent source area did not change significantly during that time interval, despite the large changes in dust concentration levels, we conclude that the differences in dustiness must have been due to changes in wind velocity, and hence the effectiveness of deflation and transportation in the East Asian source area, and not to expansion or contraction of source area size or changes in source locations (Biscaye et al., 1997).
We have now correlated one glacial-age ice-core dust interval of about 3,000 years duration with the CLP, but have not yet completed analysis of other glacial or interglacial intervals. However, to the degree that the dust in the Summit ice cores represents a record of atmospheric conditions and climate in and around the region of the CLP, it constitutes a record that has a much more precise absolute stratigraphy and greater temporal resolution than any single section in the CLP. The influence of Chinese and Mongolian loess has thus been shown to extend far beyond the CLP, all the way to Greenland, and would certainly extend eastward even beyond Greenland if there were other depositories of eolian dust as well preserved as is polar ice. Perhaps we will find that the dust from the Chinese Loess Plateau and its source areas circles the entire northern hemisphere when we extend our studies to dust trapped in the ice caps of the Tibetan plateau.

\section{Pierre E. Biscaye}

Lamont-Doherty Earth Observatory of Columbia University, Palisades NY 10964, USA biscaye@ldeo.columbia.edu

\section{Francis E. Grousset}

Département Géologie et Océanographie, Université Bordeaux 1, Avenue des Facultés, 33405 Talencecedex, France, grousset@geocean.u-bordeaux.fr

\section{Erratum:}

In the newly published PAGES Science and Implementation plan figure 10 on page 158 has an incorrect reference. The correct reference is: Tabacco, I., Passerini, A., Corbelli, F., and Gorman, M. (in press) Journal of Glaciology. Determination of the surface and bed topography at Dome Concordia (East Antarctica).

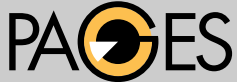

PAST GLOBAL CHANGES

PAGES International Project Office Bärenplatz 2

CH-3011 Bern, Switzerland

Tel: +41313123133

Fax: +41313123168

e-mail: pages@pages.unibe.ch

http://www.pages.unibe.ch/

Newsletter Editors: Frank Oldfield and Keith Alverson

Layout:

Niklaus Schranz 